\title{
Tenofovir Hampers the Efficacy of Sorafenib in Prolonging Overall Survival in Hepatocellular Carcinoma
}

\author{
Kung-Hao Liang $1,2,3, * \mathbb{C}$, Sung-Fang Chen ${ }^{4}$, Yu-Hua Lin ${ }^{4}$, Yu-De Chu ${ }^{5}$, Yang-Hsiang Lin ${ }^{5}{ }^{(D}$, Ming-Wei Lai ${ }^{5}$, \\ Chih-Lang Lin ${ }^{5,6,7}$ and Chau-Ting Yeh ${ }^{5,8, *}$
}

1 Department of Medical Research, Taipei Veterans General Hospital, Taipei 112, Taiwan

2 Institute of Food Safety and Health Risk Assessment, National Yang Ming Chiao Tung University, Taipei 112, Taiwan

3 Institute of Biomedical Informatics, National Yang Ming Chiao Tung University, Taipei 112, Taiwan

4 Department of Chemistry, National Taiwan Normal University, Taipei 106, Taiwan; sfchen@ntnu.edu.tw (S.-F.C.); pink3356@hotmail.com (Y.-H.L.)

5 Liver Research Center, Chang Gung Memorial Hospital, Linkou, Taoyuan 333, Taiwan; yudechu19871003@gmail.com (Y.-D.C.); yhlin0621@cgmh.org.tw (Y.-H.L.); mingweilai@gmail.com (M.-W.L.); wn49792000@yahoo.com.tw (C.-L.L.)

6 Liver Research Unit, Keelung Chang Gung Memorial Hospital, Keelung 204, Taiwan

7 Community Medicine Research Center, Keelung Chang Gung Memorial Hospital, Keelung 204, Taiwan

8 Molecular Medicine Research Center, Chang Gung University, Taoyuan 333, Taiwan

* Correspondence: kunghao@gmail.com (K.-H.L.); chauting@cgmh.org.tw (C.-T.Y.); Tel.: +886-2-28712121 (ext. 1296) (K.-H.L.); +886-3-3281200 (ext. 8129) (C.-T.Y.); Fax: 886-3-3282824 (C.-T.Y.)

check for updates

Citation: Liang, K.-H.; Chen, S.-F.; Lin, Y.-H.; Chu, Y.-D.; Lin, Y.-H.; Lai, M.-W.; Lin, C.-L.; Yeh, C.-T. Tenofovir Hampers the Efficacy of Sorafenib in Prolonging Overall Survival in Hepatocellular Carcinoma. Biomedicines 2021, 9, 1539. https:// doi.org/10.3390/biomedicines9111539

Academic Editors: Stephen Malnick and Neuman Manuela

Received: 5 October 2021

Accepted: 22 October 2021

Published: 26 October 2021

Publisher's Note: MDPI stays neutral with regard to jurisdictional claims in published maps and institutional affiliations.

Copyright: (c) 2021 by the authors. Licensee MDPI, Basel, Switzerland. This article is an open access article distributed under the terms and conditions of the Creative Commons Attribution (CC BY) license (https:// creativecommons.org/licenses/by/ $4.0 /)$.
Abstract: Sorafenib is a first-line treatment for patients with advanced hepatocellular carcinoma (HCC). These patients may simultaneously receive anti-hepatitis B treatment if they are viremic. The N-Acetylgalactosaminyltransferase 14 (GALNT14) gene can serve as a biomarker to guide HCC treatments. However, the enzyme substrates of its gene product, GalNAc-T14 (a glycosyltransferase), remained uncharacterized. Here, we conducted a glycoproteome-wide search for GalNAc-T14 substrates using lectin affinity chromatography followed by tandem mass spectrometry. Seventeen novel GalNAc-T14 substrates were identified. A connective map analysis showed that an antiviral drug, tenofovir, was the leading medicinal compound to down-regulate the expression of these substrates. In vitro assays showed that HCC cells were resistant to sorafenib if pretreated by tenofovir but not entecavir. Clinical analysis showed that the concomitant use of tenofovir and sorafenib was a previously unrecognized predictive factor for unfavorable overall survival (hazard ratio $=2.060$, $95 \%$ confidence interval $=[1.256,3.381], p=0.004)$ in a cohort of 181 hepatitis-B-related, sorafenibtreated HCC patients (concomitant tenofovir versus entecavir treatment; $p=0.003$ ). In conclusion, by conducting a glycoproteome-wide search for GalNAc-T14 substrates, we unexpectedly found that tenofovir was a major negative regulator of GalNAc-T14 substrates and an unfavorable anti-hepatitis B drug in HCC patients receiving sorafenib.

Keywords: drug-drug interactions; glycoproteome; targeted therapy; entecavir; hepatitis B

\section{Introduction}

Chronic hepatitis B is a major etiology of hepatocellular carcinoma (HCC) worldwide [1-11] and has been responsible for $\sim 80 \%$ of HCC in Taiwan before 1990 [12]. Antihepatitis $B$ virus $(\mathrm{HBV})$ treatments are routinely prescribed to viremic patients manifesting hepatitis flares [3,13-15]. Entecavir and tenofovir are the first-line oral antiviral drugs, which harbor high resistance barriers and can potently suppress viral replication to reduce liver necroinflammation [16-20]. On the other hand, the multikinase inhibitor sorafenib can prolong the overall survival in advanced stage HCCs [21,22]. It remained the only approved targeted therapy for late-stage HCC between 2007-2017 [23]. At this time, the drug is still being widely used worldwide, although lenvatinib and atezolizumab/bevacizumab 
have gradually taken over as the first-line treatments. Sorafenib and oral-antiviral drugs are often given simultaneously to HCC patients who have been HBV viremic. Most patients continue to receive oral antiviral drugs after the viral loads have been suppressed to undetectable levels by treatments, to prevent future viral reactivation due to the stopping of treatment [20]. Despite the concomitant use of sorafenib and oral-antiviral drugs, few investigations have been conducted on their mutual interfering effects.

We previously identified that genomic variants were associated with chemotherapeutic response in late-stage HCCs [24]. A series of studies showed that the genotype of a genomic variant rs9679162, located on the Polypeptide N-Acetylgalactosaminyltransferase 14 (GALNT14) gene, was consistently associated with the treatment outcome of intermediate and advanced HCC [24-29]. Additionally, GALNT14 genotypes were associated with the expression levels of their protein product, GalNac-T14, which had been shown to mediate the oncogenesis and/or treatment responses in several other cancers, including cholangiocarcinoma [30], colon cancer [31], esophageal cancer [32], neuroblastoma [33], lung cancer [34], and breast cancer [35]. These findings implicated the involvement of GalNac-T14 in cancer biology, offering effective biomarkers to guide anticancer treatments, such as choosing between systemic chemotherapy, hepatic arterial infusion chemotherapy, and sorafenib in HCCs [29]. GALNT14 also possesses other functions less relevant to cancer. A genome-wide investigation of consanguineous families showed that damaging Mendelian mutations in GALNT14 causes embryonic lethality, suggesting an irreplaceable role of GalNac-T14 in human development [36]. Germline mutations were also found in a recent study of the congenital disorders of glycosylation [37]. Finally, a genomic screening of familial neuroblastoma also identified function-disrupting germline mutations, which were responsible for the cancer occurrence [33].

GALNT14 is the gene encoding for the GalNAc-T14 glycosyltransferase. Its major function is to enable post-translational glycosylation by adding N-acetyl-D- galactosamine residues to serine or threonine residues of its substrates [38]. The glycosylation then affected the cellular and physiological functions, which may underlie patients' clinical outcome. Unfortunately, the enzyme substrates of GalNAc-T14, performing anticancerrelated functions, remained largely unknown. Thus, we were motivated to conduct a glycoproteome-wide exploration of GalNAc-T14 substrates to further elucidate their clinical implications.

\section{Materials and Methods}

\subsection{Establishing HCC Cell Lines with GalNAc-T14 Overexpression}

The GALNT14 open reading frame DNA, amplified from cDNA of J7 cells using primers, forward: atcgGCGGCCGCatgcggegcetgactcgtcg and reverse: atcgGCGGCCGCttaagagctcaccatgtccc, franking with the NotI cutting site (capitalized sequences), was inserted into pRC/CMV plasmid (Thermo Fisher Scientific, Waltham, MA, USA) using the restriction enzyme digestion/ligation method, which was then transfected to HCC cell lines, Huh7, J7, and Mahlavu, to generate stable GalNAc-T14 overexpressing cells. Corresponding mock control cell lines were also established with only the plasmid vector transfected. Western blotting using the antibody ab86526 (Abcam, Cambridge, UK) was performed to confirm the successful expression of GalNAc-T14 protein in the cells.

\subsection{Identification of GalNAc-T14 Substrates}

We employed the lectin-enriched proteomic approach to identify the GalNAc-T14 substrates expressed in the GalNAC-T14 overexpressing Huh7, J7, and Mahlavu cells but not (or less) in controls. Total proteins were extracted from these cells using the M-PER Mammalian Protein Extraction Reagent (Thermo Fisher Scientific, Waltham, MA, USA), in conjunction with HaltTM Protease Inhibitor Cocktail (Thermo Fisher Scientific, Waltham, MA, USA). Glycoproteins were then captured using a self-made lectin affinity GVS Centrex Centrifuge Filter (GVS Gruppo, Bologna, Italy), packed with Peanut Agglutin (PNA) and Vicia Villosa Lectin (VVA) (Vector Laboratories, Burlingame, CA, USA), which can bind 
to the carbohydrate sequence Gal- $\beta(1-3)$-GalNAc (N-acetylgalactosamine galactose, a.k.a. Thomsen-Friedenreich antigen, 365 daltons) and GalNAc (a.k.a. Tn antigen) respectively. The captured proteins were then eluted, subjected to dialysis, quantitated, trypsin-digested, desalted, and then identified using ultrahigh performance liquid chromatography/tandem mass spectrometry (UPLC-MS/MS).

UPLC was performed on NanoACQUITY (Waters, Milford, MA, USA) using a labmade pre-column $(100 \mu \mathrm{m} \times 2 \mathrm{~cm})$ packed with C18 AQ $200 \AA 5 \mathrm{mg}$ (Michrom bioresources, CA, USA) dissolved in $1 \mathrm{~mL}$ methanol, followed by an analytical column $(75 \mu \mathrm{m} \times 10 \mathrm{~cm})$ packed with C18 $100 \AA$, 5 mg (Macherey-Nagel, Düren, Germany) dissolved in $1 \mathrm{~mL}$ methanol. The mobile phase A was $0.1 \%$ formic acid (FA) in $100 \% \mathrm{H}_{2} \mathrm{O}$, while the mobile phase B was $0.1 \%$ FA in $100 \%$ acetonitrile. Samples were loaded to UPLC-MS/MS with a $140 \mathrm{~min}$ gradient of $2 \%$ B for $5 \mathrm{~min}, 2-40 \%$ B for $95 \mathrm{~min}, 40-80 \%$ B for $5 \mathrm{~min}, 80 \%$ B for $5 \mathrm{~min}$, and $80-2 \%$ B for $5 \mathrm{~min}$, followed by $25 \mathrm{~min}$ at $2 \% \mathrm{~B}$.

Tandem mass spectrometry was performed on LTQ-XLTM (Thermo Fisher Scientific, Waltham, MA, USA), which was controlled by the Xcalibur (version 2.1) software. A $2.0 \mathrm{kV}$ spray voltage was applied through a liquid junction. The temperature of the ion transfer capillary was set to $200{ }^{\circ} \mathrm{C}$. A full scan was performed for ions in the range of $\mathrm{m} / \mathrm{z}$ 350-2000. Precursor ions with multiple (2 4) charges then proceeded collision-induced dissociation to generate fragment ions for the identification. MSConvert was used to convert the mass spectrum into mgf files, then analyzed by the Mascot software with precursor mass tolerances of $\pm 1.5 \mathrm{Da}$ and fragment mass tolerances of $\pm 0.6 \mathrm{Da}$ (Figure $1 \mathrm{~A}$ ).

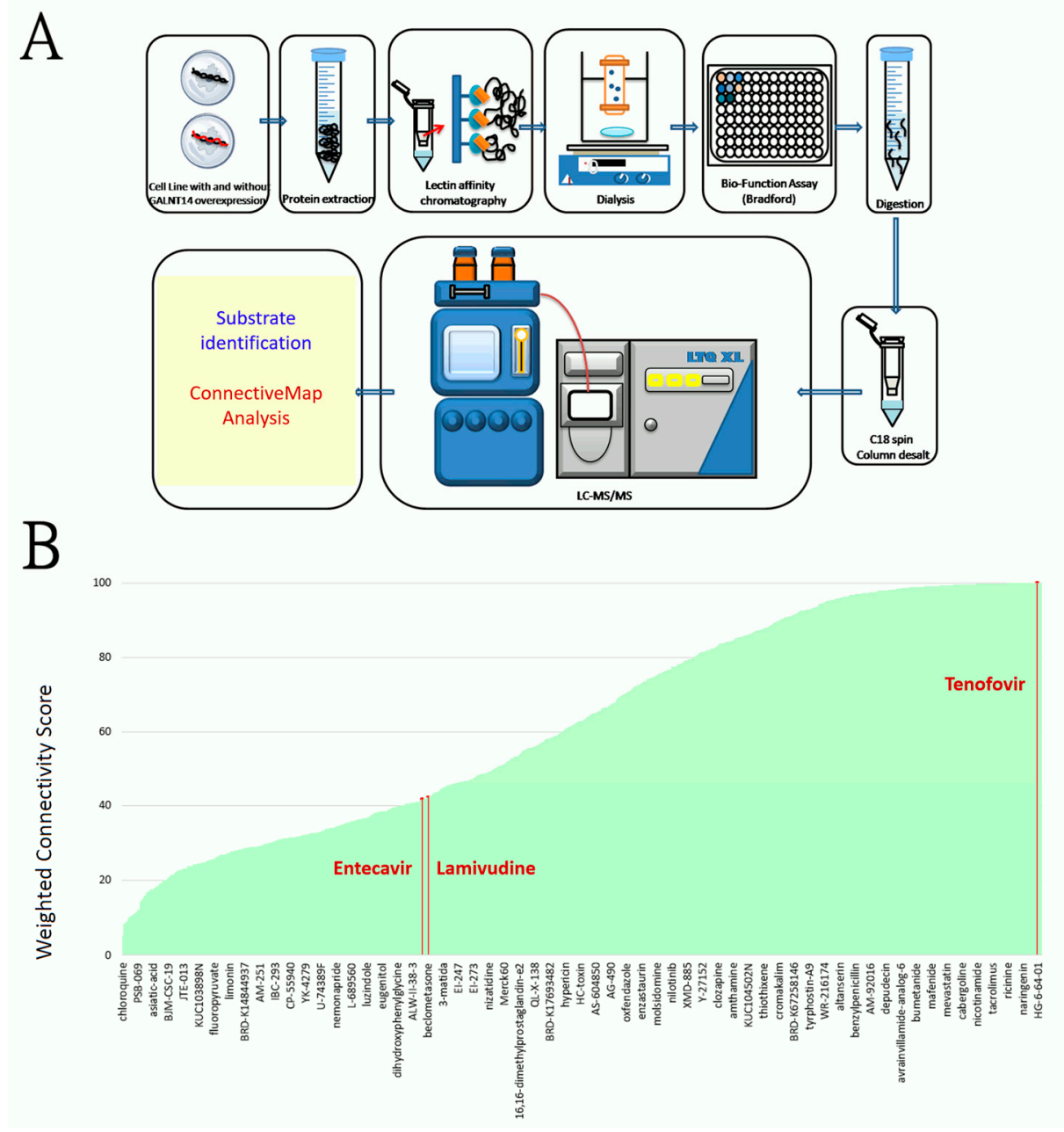

Figure 1. (A) The schematic diagram of the technical approach of detecting GalNAc-T14 substrates, 
comprising a lectin-affinity chromatography and UPLC-tandem mass spectrometry, followed by a protein identification procedure and a connective map analysis. (B) An extensive list of 1085 medicinal compounds (in the X-axis) ranked by their effects of down-regulating the GalNAcT14 substrates. The effects were shown as the weighted connectivity score (marked in the Y axis). One representative compound per every 18 compounds were marked in the $\mathrm{X}$ axis to avoid an over complicated plot. The oral anti-HBV drug tenofovir is a leading compound for the suppression. Additionally, lamivudine ranked 723, while entecavir ranked 729 in the compound list sorted by the score.

\subsection{O-Glycosylation Site Prediction}

We analyzed the O-GalNAc glycosylation sites of the identified GalNAc-T14 substrates using the NetOGlyc (4.0) online server at the site (https://services.healthtech.dtu.dk/ service.php?NetOGlyc-4.0 (accessed on 20 June 2017)). This is a neural network based system that has learned the sequence features of the O-GalNAc glycosylation site detected by the Simple Cell technology [38]. The full-length protein sequences of the identified substrates were submitted to the online system, and the top hits were documented.

\subsection{Connective Map Analysis}

We used the online resource Connective Map at the following website (https: / clue. io/cmap (accessed on 5 September 2019)) [39-41]. We entered the list of GalNAc-T14 substrates in the "Down-regulated genes" input box, asking the system to search for compounds that can suppress these genes.

\subsection{Patients}

This study was approved by the institutional review board of Chang Gung Memorial Hospital, Taiwan, and conducted according to the ethical principles in the declaration of Helsinki. All patients were adults and had given informed consent. Clinical data from 181 patients (Jan 2010 to Jan 2020) were retrieved from the Liver Research Center for analysis. All these HCC patients were in Barcelona Clinic Liver Cancer (BCLC) stage C or in BCLC stage B but were not suitable for trans-arterial chemoembolization treatment. All patients received sorafenib treatment and were positive for HBV surface antigen.

\section{Results}

\subsection{Identification of Substrates of the GalNAc-T14 Glycosyltransferase}

Substrates of the GalNAc-T14 glycosyltransferase were identified using a series of methods comprising lectin affinity chromatography, ultra-performance liquid chromatography, and tandem mass spectrometry (Figure 1A). We employed HCC cell lines (Huh7, J7 and Mahlavu) transfected by the GALNT14-expressing plasmids or the empty vectors (controls) and identified 305 proteins that were glycosylated to a higher degree in the presence of GalNAc-T14. Among them, 17 proteins were repetitively captured by different lectins and identified in different cell lines (Table 1). Particularly, proteins of EIF3G, SRSF8, SRP14, and ACTB were detected in five experimental settings (Table 1).

\subsection{Tenofovir Is a Leading Drug That Down-Regulates GalNAc-T14 Substrates in a Connective Map Analysis}

The connective map is an important online resource offering the relationship between diseases, genes, and drugs for biomedical research $[39,40]$. This system is capable of evaluating an extensive list of medicinal compounds with respect to their effects on gene expression perturbations in culture cells [39-41]. It is therefore ideal for finding drugs that can elicit specific alterations of a given set of genes. We therefore searched for drugs that could antagonize the GalNAc-T14 substrates in Table 1 using the connective map. A total of 1085 medicinal compounds were found to be capable of down-regulating these substrates, with different levels of strengths indicated by the weighted connectivity score in Figure 1B [41]. Among these compounds, nicardipine, atorvastatin, and tenofovir are the 
three leading drugs with the highest score ( 100). Tenofovir is of particular interest as it is highly relevant in HBV-related HCC patients. We then scrutinized all the oral anti-HBV drugs in the connective map. Lamivudine ranked 723, while entecavir ranked 729 in their effects of suppressing expression of GalNAc-T14 substrates (Figure 1B). Adefovir and telbivudine, on the other hand, were not included in the connective map dataset.

Table 1. List of O-glycosylated proteins identified in the evaluation of GalNAc-T14 substrates. We evaluated three cell lines, Huh7, J7, and Mahlavu, and employed two lectins, Peanut Agglutin (PNA) and Vicia Villosa Lectin (VVA), for the capturing. Glycosylated amino acids estimated by the NetOGlyc 4.0 Server are shown together with their franking sequences.

\begin{tabular}{|c|c|c|c|c|c|c|c|c|}
\hline Item & $\begin{array}{c}\text { Gene } \\
\text { Symbol }\end{array}$ & Chr & UniPort ID & $\begin{array}{l}\text { SwissPort } \\
\text { ID }\end{array}$ & $\begin{array}{c}\text { Franking Sequence of } \\
\text { Glycosylated } \\
\text { Amino Acid }\end{array}$ & $\begin{array}{l}\text { Location of } \\
\text { Glycosylation }\end{array}$ & $\begin{array}{l}\text { Protein } \\
\text { Length }\end{array}$ & Protein Name \\
\hline 1 & EIF3G & 19 & EIF3G_HUMAN & O75821 & 220-GASRRGESMQ-231 & 223 & 320 & $\begin{array}{l}\text { Eukaryotic } \\
\text { translation initiation } \\
\text { factor } 3 \text { subunit } G\end{array}$ \\
\hline 2 & SRSF8 & 11 & SRSF8_HUMAN & Q9BRL6 & 240-RSRSRSSSMT-251 & 250 & 282 & $\begin{array}{l}\text { Serine/arginine-rich } \\
\text { splicing factor } 8\end{array}$ \\
\hline 3 & SRP14 & 15 & SRP14_HUMAN & P37108 & 120-АТАРТТААТТ-131 & 125 & 136 & $\begin{array}{l}\text { Signal recognition } \\
\text { particle } 14 \mathrm{kDa} \\
\text { protein }\end{array}$ \\
\hline 4 & АСТВ & 7 & ACTB_HUMAN & P60709 & 50-DSYVGDEAQS-61 & 60 & 375 & $\begin{array}{l}\text { Actin, cytoplasmic } 1 \\
\text { (Beta-actin) }\end{array}$ \\
\hline 5 & HNRNPA1L2 & 13 & RA1L2_HUMAN & Q32P51 & 180-LPKQEMASAS-191 & 188 & 320 & $\begin{array}{l}\text { Heterogeneous } \\
\text { nuclear } \\
\text { ribonucleoprotein } \\
\text { A1-like } 2\end{array}$ \\
\hline 6 & NAP1L1 & 12 & NP1L1_HUMAN & P55209 & 280-GRGTVRTVTK-291 & 284 & 391 & $\begin{array}{l}\text { Nucleosome } \\
\text { assembly protein } \\
\text { 1-like } 1\end{array}$ \\
\hline 7 & RPL27 & 17 & RL27_HUMAN & P61353 & 50-RKVTAAMGKK-61 & 54 & 136 & $\begin{array}{l}60 S \text { ribosomal } \\
\text { protein L27 }\end{array}$ \\
\hline 8 & CAPZA2 & 7 & CAZA2_HUMAN & P47755 & 120-RTSVETALRA-131 & 123 & 286 & $\begin{array}{l}\text { F-actin-capping } \\
\text { protein subunit } \\
\text { alpha-2 }\end{array}$ \\
\hline 9 & YBX2 & 17 & YBOX2_HUMAN & Q9Y2T7 & 300-ETKPSQGPAD-311 & 305 & 364 & $\begin{array}{l}\text { Y-box-binding } \\
\text { protein } 2\end{array}$ \\
\hline 10 & RPL6 & 12 & RL6_HUMAN & Q02878 & 120-VPRKLLSHGK-131 & 127 & 288 & $\begin{array}{l}60 S \text { ribosomal } \\
\text { protein L6 }\end{array}$ \\
\hline 11 & YWHAE & 17 & 1433E_HUMAN & P62258 & 60-RIISSIEQKE-71 & 65 & 255 & 14-3-3 protein epsilon \\
\hline 12 & RPL27A & 11 & RL27A_HUMAN & P46776 & 10-LRGHVSHGHG-21 & 16 & 148 & $\begin{array}{l}60 S \text { ribosomal } \\
\text { protein L27a }\end{array}$ \\
\hline 13 & RPLP1 & 15 & RLA1_HUMAN & P05386 & 80-APSTAAAPAE-91 & 83 & 114 & $\begin{array}{l}60 S \text { acidic ribosomal } \\
\text { protein } \mathrm{P} 1\end{array}$ \\
\hline 14 & RPL3 & 22 & RL3_HUMAN & P39023 & 20-RSSRHRGKVK-31 & 23 & 403 & $\begin{array}{l}60 S \text { ribosomal } \\
\text { protein L3 }\end{array}$ \\
\hline 15 & TUBA3E & 2 & TBA3E_HUMAN & Q6PEY2 & 360-TVVPGGDLAK-371 & 361 & 450 & $\begin{array}{l}\text { Tubulin alpha-3E } \\
\text { chain }\end{array}$ \\
\hline 16 & RPS26 & 12 & RS26_HUMAN & P62854 & 90-ARKDRTPPPR-101 & 96 & 115 & $\begin{array}{l}40 S \text { ribosomal } \\
\text { protein } 526\end{array}$ \\
\hline 17 & RPL17 & 18 & RL17_HUMAN & P18621 & 0-MVRYSLDPEN-11 & 5 & 184 & $\begin{array}{l}60 S \text { ribosomal } \\
\text { protein L17 }\end{array}$ \\
\hline
\end{tabular}

\subsection{Tenofovir But Not Entecavir Hampers the Anti-Tumor Capability of Sorafenib In Vitro}

We then investigated the viability of five different HCC cell lines (Huh7, J7, HepG2, Hep3B, and Alexander) pretreated by entecavir or tenofovir, followed by the treatment of sorafenib in different concentrations (Figure 2). We started from no pretreatment (shown as black viability curves), then increased the pretreatment doses of entecavir and tenofovir stepwise (Figure 2). The drug sensitivity to sorafenib in HCC cells increased as concentrations of entecavir increased (to a level much higher than therapeutic levels) in J7, Hep3B, and Alexander cells. In contrast, the drug sensitivity to sorafenib reduced as the concentration of tenofovir increased ( 1 to 2 logs of the therapeutic concentrations) in Huh7, J7, and HepG2 cells. In Alexander cells, treatment with the highest concentrations of tenofovir 
(green line, $5000 \mathrm{ng} / \mathrm{mL}$ ) did not induce drug resistance. The in-vitro dose-escalating assays showed a tenofovir-induced resistance to sorafenib in HCC cells.

A
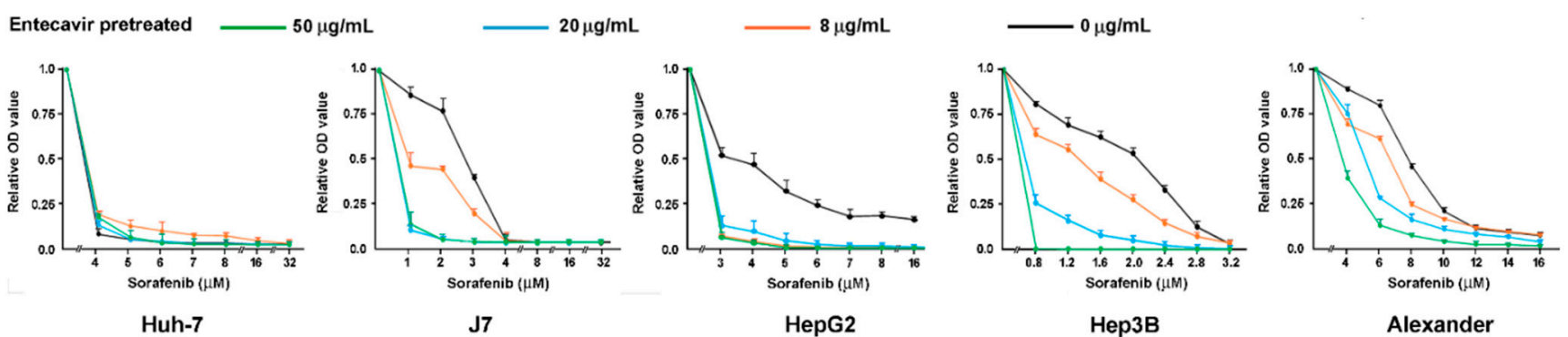

B

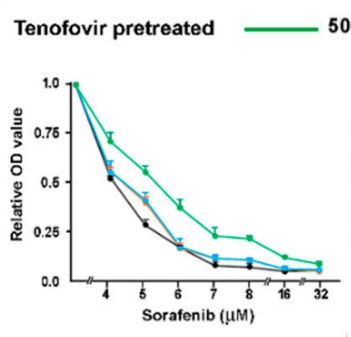

Huh-7

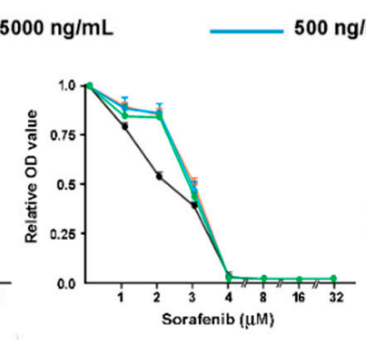

J7

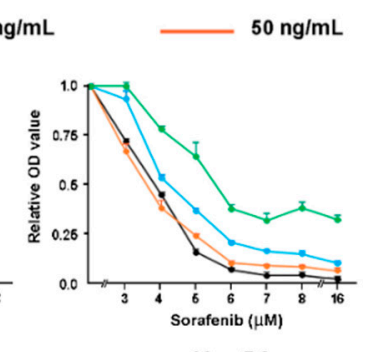

HepG2

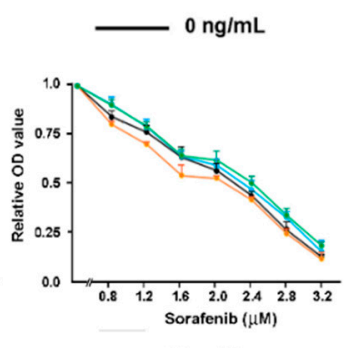

Hep3B

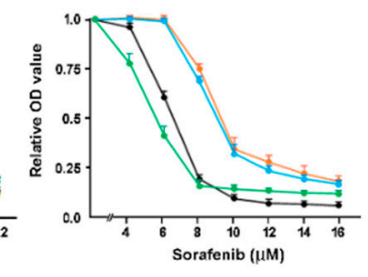

Alexander

Figure 2. The dose-escalating assays of sorafenib treatment in reducing the viability of five different HCC cell lines, Huh7, J7, HepG2, Hep3B, and Alexander, which have been pretreated by (A) entecavir or (B) tenofovir in a wide range of concentrations.

\subsection{Patients Simultaneously Treated by Sorafenib and Tenofovir Have Shorter Overall Survival than Those Treated by Sorafenib and Entecavir}

The in vitro interactive effect of tenofovir and sorafenib motivated us to investigate real-world clinical data. A total of $181 \mathrm{HBV}$-related HCC patients treated by sorafenib in Chang Gung Memorial Hospital were enrolled (Table 2). The average age at the start of sorafenib treatment was 60.4 years old. The majority of patients were male $(88.4 \%$, Table 2$)$. Twelve patients were co-infected by hepatitis $C(6.6 \%)$. No patient was co-infected by human immunodeficiency virus (HIV). A total of 67 patients were alcoholic (37.0\%). Liver cirrhosis was found in most of the patients (84.0\%). A total of 63 patients received no oral-antiviral drugs during the sorafenib treatment (35.4\%). A total of 96 patients received entecavir $(53.0 \%)$, while 22 patients received tenofovir $(12.2 \%)$. No significant differences in clinical characteristics were found between these patients receiving different treatments (Table 2).

We performed a Cox proportional hazards model analysis for the clinical factors of these patients with respect to the overall survival. Among them, liver cirrhosis, distant metastasis, ascites, albumin concentrations, bilirubin, AST, ALT, neutrophil, hemoglobin, and tenofovir co-treatment manifested statistically significant association with overall survival (Table 3). As such, tenofovir co-treatment was a previously unrecognized predictive factor for shorter overall survival (Hazard ratio $=2.060,95 \%$ confidence interval $=[1.256$, 3.381], $p=0.004)$. The overall survival associations of these factors were re-calculated using Kaplan-Meier plots (Figure 3). Patients with tenofovir treatment had significantly shorter overall survival than those without oral-antiviral treatments $(\log$-rank $p=0.024$, Figure 3A), those with entecavir $(p=0.003$, Figure $3 \mathrm{~A})$, and the latter two groups combined $(p=0.004$, Figure 3B). 
Table 2. Baseline clinical characteristics of advanced HBV-related HCC patients treated by sorafenib with or without NUC.

\begin{tabular}{|c|c|c|c|c|c|}
\hline Variables & All Patients & Entecavir Used & Tenofovir Used & No Antiviral Used & $p^{*}$ \\
\hline Number of patients & 181 & 96 & 22 & 63 & \\
\hline Age, years, mean $\pm S D$ & $60.4 \pm 12.3$ & $58.7 \pm 11.3$ & $60.6 \pm 12.9$ & $63.0 \pm 13.2$ & 0.104 \\
\hline Sex, Male $(\%)$ & $160(88.4 \%)$ & $87(90.6 \%)$ & $20(90.9 \%)$ & $53(84.1 \%)$ & 0.423 \\
\hline Anti-HCV, positive (\%) & $12(6.6 \%)$ & $5(5.2 \%)$ & $1(4.5 \%)$ & $6(9.5 \%)$ & 0.517 \\
\hline Alcoholism, Yes (\%) & $67(37.0 \%)$ & $37(38.5 \%)$ & $10(45.5 \%)$ & $20(31.7 \%)$ & 0.468 \\
\hline ECOG status, ">0" (\%) & $43(23.8 \%)$ & $24(25.0 \%)$ & $6(27.3 \%)$ & $13(20.6 \%)$ & 0.752 \\
\hline Cirrhosis, Yes (\%) & $152(84.0 \%)$ & $85(88.5 \%)$ & $19(86.4 \%)$ & $48(76.2 \%)$ & 0.11 \\
\hline Portal vein thrombosis, Yes (\%) & $98(54.1 \%)$ & $56(58.3 \%)$ & $14(63.6 \%)$ & $28(44.4 \%)$ & 0.145 \\
\hline Distant metastasis, Yes (\%) & $73(40.3 \%)$ & $37(38.5 \%)$ & $9(40.9 \%)$ & $27(42.9 \%)$ & 0.862 \\
\hline BCLC stage $B$, Yes $(\%) * *$ & $26(14.4 \%)$ & $15(15.6 \%)$ & $3(13.6 \%)$ & $8(12.7 \%)$ & 0.871 \\
\hline Size, $\mathrm{cm}$, mean $\pm \mathrm{SD}$ & $5.9 \pm 4.3$ & $5.6 \pm 4.1$ & $5.7 \pm 4.6$ & $6.5 \pm 4.6$ & 0.411 \\
\hline Ascites, Yes (\%) & $45(24.9 \%)$ & $27(28.1 \%)$ & $7(31.8 \%)$ & $11(17.5 \%)$ & 0.227 \\
\hline AFP, ng/mL, median (range) & $241.8(0.8$ to 831318$)$ & $238.4(1.7$ to 831318$)$ & $216.9(4.7$ to 84144$)$ & $259.0(0.8$ to 510606$)$ & 0.277 \\
\hline $\begin{array}{l}\text { HBV-DNA, } \times 10^{6} \text { copies } / \mathrm{mL} \text {, median } \\
\text { (range) \# }\end{array}$ & $0.0(0.0$ to 112.9$)$ & $0.0(0.0$ to 0.0$)$ & $0.0(0.0$ to 0.0$)$ & $0.0(0.0$ to 112.9$)$ & 0.145 \\
\hline Albumin, $\mathrm{g} / \mathrm{dL}$, mean $\pm \mathrm{SD}$ & $3.7 \pm 0.6$ & $3.8 \pm 0.5$ & $3.8 \pm 0.6$ & $3.7 \pm 0.7$ & 0.32 \\
\hline Bilirubin, $\mathrm{mg} / \mathrm{dL}$, mean $\pm \mathrm{SD}$ & $1.2 \pm 1.7$ & $1.1 \pm 2.0$ & $1.2 \pm 0.6$ & $1.2 \pm 1.4$ & 0.934 \\
\hline Prothrombin time, sec, mean \pm SD & $12.2 \pm 1.7$ & $12.4 \pm 2.0$ & $11.9 \pm 1.2$ & $11.9 \pm 1.2$ & 0.143 \\
\hline Creatinine, $\mathrm{mg} / \mathrm{dL}$, mean $\pm \mathrm{SD}$ & $0.9 \pm 0.6$ & $0.9 \pm 0.7$ & $0.9 \pm 0.4$ & $0.9 \pm 0.4$ & 0.995 \\
\hline $\mathrm{AST}, \mathrm{U} / \mathrm{L}$, mean $\pm \mathrm{SD}$ & $74.6 \pm 68.4$ & $75.9 \pm 76.2$ & $72.9 \pm 44.2$ & $73.2 \pm 63.2$ & 0.966 \\
\hline $\mathrm{ALT}, \mathrm{U} / \mathrm{L}$, mean $\pm \mathrm{SD}$ & $46.0 \pm 38.3$ & $45.5 \pm 42.0$ & $53.2 \pm 44.0$ & $44.3 \pm 29.5$ & 0.634 \\
\hline White blood cell, $10^{9} / \mathrm{L}$, mean $\pm \mathrm{SD}$ & $6.3 \pm 3.0$ & $6.1 \pm 2.9$ & $5.4 \pm 2.0$ & $6.9 \pm 3.3$ & 0.108 \\
\hline Neutrophil, percentage, mean \pm SD & $66.1 \pm 12.9$ & $66.1 \pm 13.8$ & $62.2 \pm 11.7$ & $67.3 \pm 11.7$ & 0.271 \\
\hline Hemoglobin, g/dL, mean \pm SD & $12.4 \pm 2.0$ & $12.4 \pm 2.1$ & $12.4 \pm 1.5$ & $12.3 \pm 2.0$ & 0.999 \\
\hline Platelet, $10^{9} / \mathrm{L}$, mean \pm SD & $168.3 \pm 93.2$ & $162.3 \pm 90.2$ & $143.5 \pm 89.8$ & $186.2 \pm 97.1$ & 0.118 \\
\hline Previous treatment, Yes (\%) & $161(89.0 \%)$ & $89(92.7 \%)$ & $20(90.9 \%)$ & $52(82.5 \%)$ & 0.129 \\
\hline
\end{tabular}

* $p$ : the significance level for comparing the entecavir used, tenofovir used, and no antiviral used patients. Chi-square tests were used for categorical data, while analysis of variance (ANOVA) tests were used for numerical data. HCV, hepatitis C virus; ECOG, Eastern Cooperative Oncology Group; AFP, alpha-fetoprotein; AST, aspartate transaminase; ALT, alanine transaminase. ${ }^{* *}$ : The remaining patients were all BCLC stage C. \#: The lower quantification limit was 116 copies $/ \mathrm{mL}$. All patients treated by entecavir or tenofovir had HBV-DNA < lower quantification limit.

Table 3. Cox proportional hazard analysis in $181 \mathrm{HBV}$-related HCC patients for clinical variables in relationship to overall survival.

\begin{tabular}{|c|c|c|}
\hline Variables & HR $(95 \%$ CI $)$ & $p$ \\
\hline Age, per year & $0.992(0.997,1.008)$ & 0.344 \\
\hline Sex, Male $=1$ & $0.741(0.405,1.356)$ & 0.331 \\
\hline Anti-HCV, positive $=1$ & $0.736(0.300,1.809)$ & 0.505 \\
\hline Alcoholism, positive $=1$ & $1.233(0.842,1.806)$ & 0.281 \\
\hline ECOG status, ">0" = 1 & $1.324(0.845,2.075)$ & 0.221 \\
\hline Cirrhosis, Yes = 1 & $2.160(1.182,3.946)$ & 0.012 \\
\hline Portal vein thrombosis, Yes $=1$ & $1.098(0.755,1.599)$ & 0.624 \\
\hline Distant metastasis, Yes $=1$ & $1.488(1.023,2.164)$ & 0.038 \\
\hline Size, per $\mathrm{cm}$ & $1.020(0.978,1.065)$ & 0.353 \\
\hline Ascites, Yes $=1$ & $2.535(1.676,3.833)$ & $<0.001$ \\
\hline AFP, per $1000 \mathrm{ng} / \mathrm{mL}$ & $1.001(0.999,1.003)$ & 0.234 \\
\hline Albumin, per g/dL & $0.532(0.380,0.745)$ & $<0.001$ \\
\hline Bilirubin, per $\mathrm{mg} / \mathrm{dL}$ & $1.340(1.175,1.528)$ & $<0.001$ \\
\hline Prothrombin time, per sec & $0.995(0.877,1.129)$ & 0.941 \\
\hline Creatinine, per mg/dL & $1.176(0.839,1.650)$ & 0.347 \\
\hline AST, per U/L & $1.008(1.005,1.010)$ & $<0.001$ \\
\hline ALT, per U/L & $1.006(1.002,1.011)$ & $<0.006$ \\
\hline White blood cell, per $\times 10^{9} / \mathrm{L}$ & $1.069(0.999,1.144)$ & 0.053 \\
\hline Neutrophil, per percentage & $1.032(1.015,1.050)$ & $<0.001$ \\
\hline Hemoglobin, per $\mathrm{g} / \mathrm{dL}$ & $0.863(0.782,0.953)$ & $<0.003$ \\
\hline Platelet, per $\times 10^{9} / \mathrm{L}$ & $0.999(0.997,1.002)$ & 0.611 \\
\hline Previous treatment, Yes $=1$ & $1.052(0.596,1.855)$ & 0.862 \\
\hline Tenofovir used, Yes = 1 & $2.060(1.256,3.381)$ & $<0.004$ \\
\hline Entecavir used, Yes $=1$ & $0.798(0.549,1.159)$ & 0.235 \\
\hline No antiviral used, Yes $=1$ & $0.797(0.533,1.191)$ & 0.268 \\
\hline
\end{tabular}

HCV, hepatitis C virus; ECOG, Eastern Cooperative Oncology Group; AFP, alpha-fetoprotein; AST, aspartate transaminase; ALT, alanine transaminase. $p$ values below 0.05 are shown in bold face. 

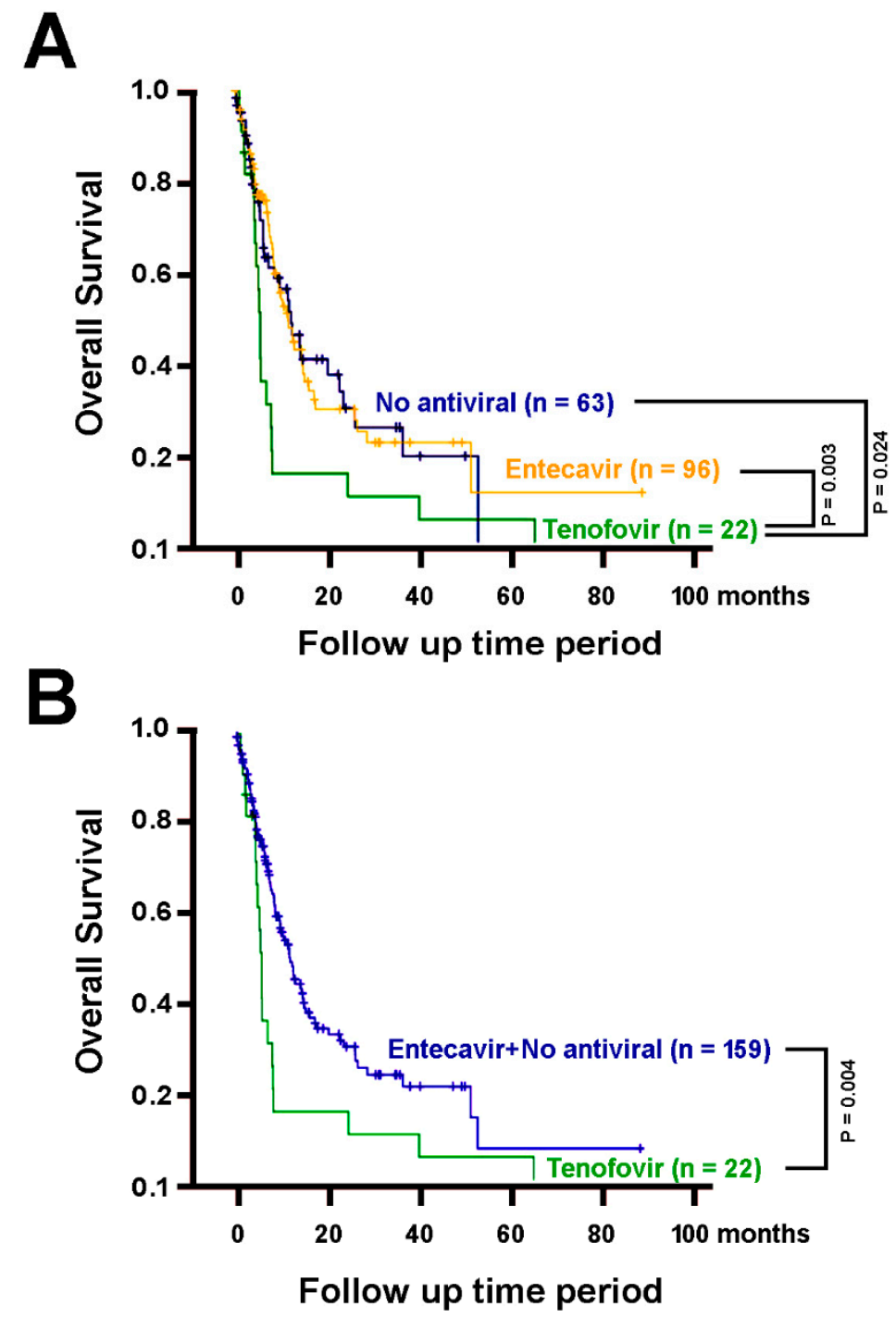

Figure 3. The overall survival of patients treated by sorafenib alone $(n=63)$ or in combination with entecavir $(n=96)$ or tenofovir $(n=22)$. (A) Patients with tenofovir treatment, in addition to sorafenib treatment, have significantly poorer overall survival than those with no oral-antiviral treatments $(p=0.024)$, with entecavir $(p=0.003)$. (B) Patients with tenofovir treatment have significantly poorer overall survival than the group comprising both those without oral-antiviral treatments and those with entecavir $(p=0.004)$.

\section{Discussion}

It is a mandate for clinicians to offer optimal treatments to cancer patients, especially when the treatments carry profound side effects and their efficacies are limited. The present study led to the unexpected finding that anti-HBV agents (entecavir, lamivudine, and tenofovir) had different strengths in down-regulating GalNAc-T14 substrates, whereas GALNT14 genotypes (and thus the GalNAc-T14 levels) were associated with sorafenib treatment outcomes [29]. Lamivudine is no longer a first-line anti-HBV treatment and therefore not being investigated further in this study. Entecavir and tenofovir are currently the first-line treatments for chronic hepatitis B [16-20]. They are both nucleus(t)ide analogs and are commonly perceived to be equally effective in viral suppressions. We conducted a series of dose-escalating assays demonstrating that HCC cells were more resistant to sorafenib in the presence of tenofovir (pretreatment) than entecavir. Additionally, clinical investigation in patients treated by sorafenib showed that the use of tenofovir was a previously overlooked risk factor for unfavorable survival. 
Nucleus(t)ide analogs for chronic hepatitis B are often prescribed in HCC patients who remained HBV viremic. The present investigation offered the first piece of evidence that antiviral treatments could interfere with anti-HCC treatments such as sorafenib. This interference likely manifested through alterations of GalNAc-T14 substrate levels. Tenofovir can also be used to treat human immunodeficiency virus (HIV) infection. A previous small retrospective study of HIV and HCC patients treated by sorafenib and highly active anti-retroviral therapy (HAART) concluded that HAART was reasonably safe and effective [42]. However, no detailed comparisons were made between different antivirals in term of survival. In light of the present study, this issue should be clarified.

The connective map intended to offer the gateway between diseases, genes, and drugs $[39,40]$, by quantifying genome-wide perturbation (up-regulation and/or downregulation) of genes at the RNA levels, measured by gene expression microarray. The system is often queried by a set of genes, to see the relative positions of these genes in the total gene list ranked by the perturbation effect, i.e., a concept similar to the gene set enrichment analysis (GSEA) [43]. Here, we utilized the list of the GalNAc-T14 substrates, which were proteins, and asked the system to find medicinal compounds that could downregulate the RNA expression profile of genes encoding the GalNAc-T14 substrates. If the RNA is down-regulated, then the corresponding proteins should also be down-regulated. As for the molecular mechanistic scenario, there are two possibilities that tenofovir could serve as an antagonist or a mimic to GalNAc-T14. Firstly, these substrates after being O-glycosylated (by GalNAc-T14) are functionally up-regulated. Addition of tenofovir could reduce the expression of these substrates and thus counteract GalNAc-T14 function. In the literature, the ribosomal proteins RPL5 and RPL11 are critical for the proper function of the tumor suppressor Tp53 [44,45], and our substrates included RPL 3, 6, 17, 27, 27A, and P1. Impaired ribosomal proteins by somatic or germline loss-of-function mutations have been shown to associate with malignancy [44]. In this view, GalNAc-T14 promotes the tumor suppressor function, while tenofovir acts against it. Alternatively, it is also possible that O-glycosylation of these substrates leads to down-regulation of their function and thus promotes cancer growth. Previous studies showed that overexpression of GalNac-T14 promotes tumor growth and metastasis in several cancers [33-35]. In this view, tenofovir mimics GalNac-T14 function to promote cancer growth. At this time, it is still unclear which scenario is correct.

In the present study, after the hepatoma cells were pre-treated by tenofovir and entecavir, it was found that the cell proliferation rate did not manifest a statistically significant difference between tenofovir-treated, entecavir-treated, or untreated cells (assessed by MTT assays). Therefore, the mechanism by which tenofovir reduces the cell sensitivity to sorafenib might not be due to cell proliferation. In one of our previous publications [25], it was found that patients with the "TT" genotype in the SNP rs9679162 had better clinical outcomes, as well as higher tumor/non-tumor ratios of GalNAc-T14 protein and lower tumor/non-tumor ratios of cFLIP-S, a major anti-apoptosis protein. Down-regulation of GalNAc-T14 substrates by tenofovir might perturb this regulatory axis, resulting in enhanced anti-apoptosis effects.

\section{Conclusions}

By glycoproteomic-identification of the GalNac-T14 substrates followed by connective map analysis, we discovered that tenofovir treatment down-regulated a subset of genes highly overlapped with the genes encoding GalNac-T14 substrates. Subsequent clinical data analysis showed that HBV/HCC patients treated by sorafenib and tenofovir had a shorter overall survival compared with those treated by sorafenib and entecavir or those receiving no antiviral treatment.

Author Contributions: C.-T.Y. designed and supervised the study. K.-H.L. drafted the manuscript. S.-F.C., Y.-H.L. (Yu-Hua Lin), M.-W.L., Y.-H.L. (Yang-Hsiang Lin), Y.-D.C., and C.-L.L. collected and analyzed the data. K.-H.L. performed statistical analysis. All authors have approved the final version of the manuscript. 
Funding: This work was supported by grants from the Ministry of Science and Technology (MOST) in Taiwan (MOST 109-2314-B-075-057 and MOST 109-2113-M-003-003), the Chang Gung Memorial Hospital Medical Research Program, Linkou (CMRPG3F1601-3), and Taipei Veterans General Hospital (VGH-107-C-083).

Institutional Review Board Statement: This study was approved by the institutional review board of Chang Gung Memorial Hospital, Taiwan (Approval Code: 106-0771C and 106-0789C, approved 5 April 2017), and conducted according to the ethical principles in the declaration of Helsinki.

Informed Consent Statement: All patients were adults and had given informed consent.

Data Availability Statement: Data will be available for academic scientists upon reasonable request to the corresponding author.

Acknowledgments: The authors would like to thank Kowa Chen and Tan-Chi Fan for recommending PNA and VVA lectins to be used in the glycoproteome assay. Technical assistances by Chi-Yun Sun are gratefully appreciated.

Conflicts of Interest: The authors declared no conflicting interest.

\section{References}

1. Lavanchy, D. Hepatitis B virus epidemiology, disease burden, treatment, and current and emerging prevention and control measures. J. Viral Hepat. 2004, 11, 97-107. [CrossRef]

2. Lim, S.G.; Mohammed, R.; Yuen, M.-F.; Kao, J.-H. Prevention of hepatocellular carcinoma in hepatitis B virus infection. J. Gastroenterol. Hepatol. 2009, 24, 1352-1357. [CrossRef]

3. $\quad$ Lin, S.-M.; Yu, M.-L.; Lee, C.-M.; Chien, R.-N.; Sheen, I.S.; Chu, C.-M.; Liaw, Y.-F. Interferon therapy in HBeAg positive chronic hepatitis reduces progression to cirrhosis and hepatocellular carcinoma. J. Hepatol. 2007, 46, 45-52. [CrossRef]

4. Lok, A.S.F. Hepatitis B: Liver fibrosis and hepatocellular carcinoma. Gastroentérol. Clin. Biol. 2009, 33, 911-915. [CrossRef]

5. Lok, A.S.F.; McMahon, B.J. Chronic hepatitis B. Hepatology 2007, 45, 507-539. [CrossRef]

6. Tsukuma, H.; Hiyama, T.; Tanaka, S.; Nakao, M.; Yabuuchi, T.; Kitamura, T.; Nakanishi, K.; Fujimoto, I.; Inoue, A.; Yamazaki, H.; et al. Risk Factors for Hepatocellular Carcinoma among Patients with Chronic Liver Disease. N. Engl. J. Med. 1993, 328, 1797-1801. [CrossRef]

7. Elgouhari, H.M.; Abu-Rajab Tamimi, T.I.; Carey, W.D. Hepatitis B virus infection: Understanding its epidemiology, course, and diagnosis. Clevel. Clin. J. Med. 2008, 75, 881-889. [CrossRef]

8. Ganem, D.; Prince, A.M. Hepatitis B Virus Infection-Natural History and Clinical Consequences. N. Engl. J. Med. 2004, 350, 1118-1129. [CrossRef] [PubMed]

9. Liaw, Y.-F.; Chu, C.-M. Hepatitis B virus infection. Lancet 2009, 373, 582-592. [CrossRef]

10. Pan, C.Q.; Zhang, J.X. Natural History and Clinical Consequences of Hepatitis B Virus Infection. Int. J. Med. Sci. 2005, 2, 36-40. [CrossRef] [PubMed]

11. Yim, H.J.; Lok, A.S.-F. Natural history of chronic hepatitis B virus infection: What we knew in 1981 and what we know in 2005. Hepatology 2006, 43, S173-S181. [CrossRef] [PubMed]

12. Chen, D.S. Hepatocellular carcinoma in Taiwan. Hepatol. Res. 2007, 37 (Suppl. 2), S101-S105. [CrossRef] [PubMed]

13. Lai, C.-L.; Yuen, M.-F. Prevention of hepatitis B virus-related hepatocellular carcinoma with antiviral therapy. Hepatology 2013, 57, 399-408. [CrossRef]

14. Liaw, Y.-F.; Sung, J.J.Y.; Chow, W.C.; Farrell, G.; Lee, C.-Z.; Yuen, H.; Tanwandee, T.; Tao, Q.-M.; Shue, K.; Keene, O.N.; et al. Lamivudine for Patients with Chronic Hepatitis B and Advanced Liver Disease. N. Engl. J. Med. 2004, 351, 1521-1531. [CrossRef]

15. Shen, Y.-C.; Hsu, C.; Chen, L.-T.; Cheng, C.-C.; Hu, F.-C.; Cheng, A.-L. Adjuvant interferon therapy after curative therapy for hepatocellular carcinoma (HCC): A meta-regression approach. J. Hepatol. 2010, 52, 889-894. [CrossRef] [PubMed]

16. Choi, J.; Kim, H.J.; Lee, J.; Cho, S.; Ko, M.J.; Lim, Y.-S. Risk of Hepatocellular Carcinoma in Patients Treated With Entecavir vs Tenofovir for Chronic Hepatitis B. JAMA Oncol. 2019, 5, 30. [CrossRef]

17. Flemming, J.A.; Terrault, N.A. Tenofovir vs Entecavir for Hepatocellular Carcinoma Prevention in Patients With Chronic Hepatitis B. JAMA Oncol. 2019, 5, 17. [CrossRef] [PubMed]

18. Kamal, F.; Khan, M.A.; Ahmed, A.; Nair, S. Tenofovir versus entecavir in prevention of hepatocellular carcinoma and mortality in patients with chronic hepatitis B. Gut 2020, 69, 2054-2056. [CrossRef] [PubMed]

19. Lee, S.W.; Kwon, J.H.; Lee, H.L.; Yoo, S.H.; Nam, H.C.; Sung, P.S.; Nam, S.W.; Bae, S.H.; Choi, J.Y.; Yoon, S.K.; et al. Comparison of tenofovir and entecavir on the risk of hepatocellular carcinoma and mortality in treatment-naïve patients with chronic hepatitis $B$ in Korea: A large-scale, propensity score analysis. Gut 2019, 69, 1301-1308. [CrossRef]

20. EASL. Clinical Practice Guidelines on the management of hepatitis B virus infection. J. Hepatol. 2017, 67, 370-398. [CrossRef] [PubMed] 
21. Cheng, A.L.; Kang, Y.K.; Chen, Z.; Tsao, C.J.; Qin, S.; Kim, J.S.; Luo, R.; Feng, J.; Ye, S.; Yang, T.S.; et al. Efficacy and safety of sorafenib in patients in the Asia-Pacific region with advanced hepatocellular carcinoma: A phase III randomised, double-blind, placebo-controlled trial. Lancet Oncol. 2009, 10, 25-34. [CrossRef]

22. Llovet, J.M.; Ricci, S.; Mazzaferro, V.; Hilgard, P.; Gane, E.; Blanc, J.-F.; de Oliveira, A.C.; Santoro, A.; Raoul, J.-L.; Forner, A.; et al. Sorafenib in Advanced Hepatocellular Carcinoma. N. Engl. J. Med. 2008, 359, 378-390. [CrossRef] [PubMed]

23. Huang, A.; Yang, X.-R.; Chung, W.-Y.; Dennison, A.R.; Zhou, J. Targeted therapy for hepatocellular carcinoma. Signal Transduct. Target. Ther. 2020, 5, 146. [CrossRef]

24. Liang, K.-H.; Lin, C.-C.; Yeh, C.-T. GALNT14 SNP as a potential predictor of response to combination chemotherapy using 5-FU, mitoxantrone and cisplatin in advanced HCC. Pharmacogenomics 2011, 12, 1061-1073. [CrossRef] [PubMed]

25. Liang, K.-H.; Lin, C.-L.; Chen, S.-F.; Chiu, C.-W.; Yang, P.-C.; Chang, M.-L.; Lin, C.-C.; Sung, K.-F.; Yeh, C.; Hung, C.-F.; et al. GALNT14 genotype effectively predicts the therapeutic response in unresectable hepatocellular carcinoma treated with transcatheter arterial chemoembolization. Pharmacogenomics 2016, 17, 353-366. [CrossRef]

26. Liang, K.H.; Yang, P.C.; Yeh, C.T. Genotyping the GALNT14 gene by joint analysis of two linked single nucleotide polymorphisms using liver tissues for clinical and geographical comparisons. Oncol. Lett. 2014, 8, 2215-2220. [CrossRef]

27. Lin, W.R.; Hsu, C.W.; Chen, Y.C.; Chang, M.L.; Liang, K.H.; Huang, Y.H.; Yeh, C.T. GALNT14 genotype, $\alpha$-fetoprotein and therapeutic side effects predict post-chemotherapy survival in patients with advanced hepatocellular carcinoma. Mol. Clin. Oncol. 2014, 2, 630-640. [CrossRef] [PubMed]

28. Yeh, C.-T.; Liang, K.-H.; Lin, C.-C.; Chang, M.-L.; Hsu, C.-L.; Hung, C.-F. A single nucleotide polymorphism on the GALNT14 gene as an effective predictor of response to chemotherapy in advanced hepatocellular carcinoma. Int. J. Cancer 2013, 134, 1214-1224. [CrossRef]

29. Lin, C.-C.; Hsu, C.-W.; Chen, Y.-C.; Chang, M.-L.; Liang, K.-H.; Lai, M.-W.; Lin, C.-L.; Chien, R.-N.; Lin, K.-H.; Yeh, C.-T. A GALNT14 rs9679162 genotype-guided therapeutic strategy for advanced hepatocellular carcinoma: Systemic or hepatic arterial infusion chemotherapy. Pharm. J. 2019, 20, 57-68. [CrossRef]

30. Liang, K.-H.; Yeh, T.-S.; Wu, R.-C.; Yeh, C.-N.; Yeh, C.-T. GALNT14 genotype is associated with perineural invasion, lymph node metastasis and overall survival in resected cholangiocarcinoma. Oncol. Lett. 2017, 13, 4215-4223. [CrossRef]

31. Lin, W.-R.; Chiang, J.-M.; Liang, K.-H.; Lim, S.-N.; Lai, M.-W.; Tsou, Y.-K.; Hsieh, T.-Y.; Hsu, C.-K.; Yeh, C.-T. GALNT14 Genotype Predicts Postoperative Outcome of Stage III Colorectal Cancer With Oxaliplatin as Adjuvant Chemotherapy. Medicine 2016, 95, e3487. [CrossRef] [PubMed]

32. Tsou, Y.-K.; Liang, K.-H.; Lin, W.-R.; Chang, H.-K.; Tseng, C.-K.; Yeh, C.-T. GALNT14 genotype as a response predictor for concurrent chemoradiotherapy in advanced esophageal squamous cell carcinoma. Oncotarget 2017, 8, 29151. [CrossRef]

33. De Mariano, M.; Gallesio, R.; Chierici, M.; Furlanello, C.; Conte, M.; Garaventa, A.; Croce, M.; Ferrini, S.; Paolo Tonini, G.; Longo, L. Identification of GALNT14 as a novel neuroblastoma predisposition gene. Oncotarget 2015, 6, 26335-26346. [CrossRef] [PubMed]

34. Kwon, O.-S.; Lee, H.; Kong, H.-J.; Kwon, E.-J.; Park, J.E.; Lee, W.; Kang, S.; Kim, M.; Kim, W.; Cha, H.-J. Connectivity map-based drug repositioning of bortezomib to reverse the metastatic effect of GALNT14 in lung cancer. Oncogene 2020, 39, 4567-4580. [CrossRef]

35. Song, K.-H.; Park, M.S.; Nandu, T.S.; Gadad, S.; Kim, S.-C.; Kim, M.-Y. GALNT14 promotes lung-specific breast cancer metastasis by modulating self-renewal and interaction with the lung microenvironment. Nat. Commun. 2016, 7, 13796. [CrossRef]

36. Shamseldin, H.E.; Tulbah, M.; Kurdi, W.; Nemer, M.; Alsahan, N.; Al Mardawi, E.; Khalifa, O.; Hashem, A.; Kurdi, A.; Babay, Z.; et al. Identification of embryonic lethal genes in humans by autozygosity mapping and exome sequencing in consanguineous families. Genome Biol. 2015, 16, 116. [CrossRef] [PubMed]

37. Hansen, L.; Lind-Thomsen, A.; Joshi, H.J.; Pedersen, N.B.; Have, C.T.; Kong, Y.; Wang, S.; Sparso, T.; Grarup, N.; VesterChristensen, M.B.; et al. A glycogene mutation map for discovery of diseases of glycosylation. Glycobiology 2014, 25, 211-224. [CrossRef] [PubMed]

38. Steentoft, C.; Vakhrushev, S.Y.; Joshi, H.J.; Kong, Y.; Vester-Christensen, M.B.; Schjoldager, K.T.B.G.; Lavrsen, K.; Dabelsteen, S.; Pedersen, N.B.; Marcos-Silva, L.; et al. Precision mapping of the human O-GalNAc glycoproteome through SimpleCell technology. EMBO J. 2013, 32, 1478-1488. [CrossRef] [PubMed]

39. Lamb, J. The Connectivity Map: A new tool for biomedical research. Nat. Rev. Cancer 2007, 7, 54-60. [CrossRef] [PubMed]

40. Lamb, J.; Crawford, E.D.; Peck, D.; Modell, J.W.; Blat, I.C.; Wrobel, M.J.; Lerner, J.; Brunet, J.P.; Subramanian, A.; Ross, K.N.; et al. The Connectivity Map: Using gene-expression signatures to connect small molecules, genes, and disease. Science 2006, 313, 1929-1935. [CrossRef] [PubMed]

41. Subramanian, A.; Narayan, R.; Corsello, S.M.; Peck, D.D.; Natoli, T.E.; Lu, X.; Gould, J.; Davis, J.F.; Tubelli, A.A.; Asiedu, J.K.; et al. A Next Generation Connectivity Map: L1000 Platform and the First 1,000,000 Profiles. Cell 2017, 171, 1437-1452.e1417. [CrossRef] [PubMed]

42. Berretta, M.; Di Benedetto, F.; Dal Maso, L.; Cacopardo, B.; Nasti, G.; Facchini, G.; Bearz, A.; Spina, M.; Garlassi, E.; De Re, V.; et al. Sorafenib for the treatment of unresectable hepatocellular carcinoma in HIV-positive patients. Anti-Cancer Drugs 2013, 24, $212-218$. [CrossRef] [PubMed] 
43. Subramanian, A.; Tamayo, P.; Mootha, V.K.; Mukherjee, S.; Ebert, B.L.; Gillette, M.A.; Paulovich, A.; Pomeroy, S.L.; Golub, T.R.; Lander, E.S.; et al. Gene set enrichment analysis: A knowledge-based approach for interpreting genome-wide expression profiles. Proc. Natl. Acad. Sci. USA 2005, 102, 15545. [CrossRef]

44. Goudarzi, K.M.; LindstrÖM, M.S. Role of ribosomal protein mutations in tumor development (Review). Int. J. Oncol. 2016, 48, 1313-1324. [CrossRef] [PubMed]

45. Zhou, X.; Liao, W.-J.; Liao, J.-M.; Liao, P.; Lu, H. Ribosomal proteins: Functions beyond the ribosome. J. Mol. Cell Biol. 2015, 7, 92-104. [CrossRef] [PubMed] 